\title{
Mental Health Effects of Media Exposure Following a Natural Disaster ${ }^{1}$
}

\author{
Julia Frohlich, Angela B. Lindsey, and Heidi Radunovich²
}

\section{Introduction}

Disasters are undisputed, stressful events for many people throughout the world. Within the United States alone, it is estimated that two million individuals personally experience impacts and/or property damage from disasters (Solomon, 1989). Research has continually detailed the psychological and physiological impacts of disasters, including the mental health effects of long-term media exposure during natural disasters. Given the increased use of new and traditional media during natural disasters, it is important to understand the potential mental health impacts. The purposes of this document are to (1) discuss the impacts on mental health that can be intensified via media consumption and (2) provide media consumption guidelines that can help to monitor media use and decrease negative mental health impacts.

\section{Natural Disasters and Mental Health}

Natural disasters are defined as natural hazards, uncontrollable and unexpected phenomena, and/or physical events from the natural environment which have a negative impact on societal structures (Irasema, 2002). They include hailstorms, hurricanes, lightning, tornadoes, landslides, sinkholes, tsunamis, earthquakes, volcanoes, flooding, and wildfires. In 2019, NOAA reported that the United States was impacted by 14-billion dollars' worth of disasters including three major floods, eight extreme storms, two tropical cyclones, and one wildfire event (Smith, 2019). Natural disasters can be especially devastating because they are often sudden, severe, and increasingly impactful on a global level, causing distress and disruption to many (Leaning et al., 2013).

After a natural disaster, people may experience a period of stress, anxiety, fatigue, and hopelessness. They may experience these feelings during or after the event. For most people, these feelings are temporary (Evans \& Heiberger, 2016). However, in extreme cases, a natural disaster may have psychological consequences such as post-traumatic stress disorder (PTSD) (American Psychiatric Association, 2013). Excessive or intense media exposure can exacerbate mental health challenges during and after disasters.

\section{Media Use during a Natural Disaster}

People spend a large portion of their free time online. They increasingly obtain news and other information from online sources such as social media. Social media is an important avenue for dissemination following a disaster. Media consumption can serve as a valuable tool in times of disasters and is often how individuals initially learn of disasters (FEMA, 1999). The Federal Emergency Management Agency (FEMA) suggests the media can be helpful

1. This document is FCS3360, one of a series of the Department of Family, Youth and Community Sciences, UF/IFAS Extension. Original publication date October 2021. Visit the EDIS website at https://edis.ifas.ufl.edu for the currently supported version of this publication.

2. Julia Frohlich, graduate student; Angela B. Lindsey, Ph.D., assistant professor; and Heidi Radunovich, Ph.D., associate professor, Department of Family, Youth and Community Sciences; UF/IFAS Extension, Gainesville, FL 32611.

The Institute of Food and Agricultural Sciences (IFAS) is an Equal Opportunity Institution authorized to provide research, educational information and other services

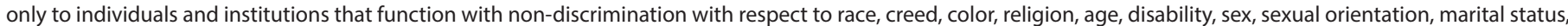

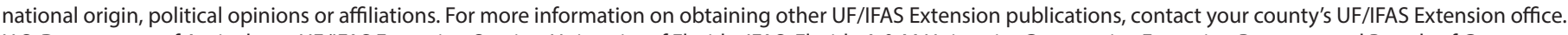
U.S. Department of Agriculture, UF/IFAS Extension Service, University of Florida, IFAS, Florida A \& M University Cooperative Extension Program, and Boards of County Commissioners Cooperating. Nick T. Place, dean for UF/IFAS Extension. 
by providing information, disseminating information (e.g., tips, supplies), and coordinating volunteers and donations.

Accurate and timely information is necessary to keep families safe and prepared before, during, and after a disaster. However, it is also important to understand the potential negative mental health effects from constant exposure to graphic images and 24-hour news cycles. Social media is uniquely poised to exacerbate negative mental health effects because of its rapid updates, personal nature, and chat features. Social media can also exacerbate negative mental health effects due to the constant updating of feeds with new information, personal opinions that can masquerade as legitimate news stories, and its ability to house a large number of stories about the same topic from different perspectives, leading to information overload (Jaeger et al., 2007). Just as the disaster itself can affect mental health conditions, such as depression or anxiety, so can media exposure before, during, and after the natural disaster.

\section{Media's Role in Mental Health during Natural Disasters}

Media exposure during a disaster can result in mental health impacts ranging from grief, fear, and anxiety, which are common, to more severe impacts such as PTSD (Rogers, 2013). Media exposure may also increase the likelihood of secondary traumatization. Media outlets often focus on devastating impacts of events so that people will take notice and tune in to watch. However, the same components that draw people in can increase stress in those who actually experienced the event, as well as in people who did not, due to repeated exposure (Neria \& Sullivan, 2011). Secondary traumatic stress can occur in people who have not experienced the disaster, because the constant media stream brings with it stress and uncertainty (Rogers, 2013).

Researchers have found links between media exposure, including via TV and Internet, during various natural disasters and the experience of strong emotional reactions and PTSD (Hall et. al., 2019; Pfefferbaum, 2014). In fact, all it takes is repeated exposure to disturbing imagery (Yeung et al., 2018), such as images present in the news following disasters, to have negative effects. The 24 -hour news cycle helps people receive important information during and after a disaster, but it can lead to negative mental health effects if people watch excessively.

Although there are disadvantages of media consumption during and after a disaster, there are advantages as well. Depending on how writers discuss disasters, they can influence perceptions of the event and increase the likelihood of community resilience (Norris, Stevens, Pfefferbaum, Wyche, \& Pfefferbaum, 2008). Furthermore, disaster survivors can utilize social media as a collective coping mechanism by sharing their stories/pictures and expressing themselves. Social media can also be used to communicate with friends and family (Tandoc \& Takahashi, 2017).

\section{Suggestions for Media Use}

Although media use is instrumental in obtaining accurate and timely information during a crisis, overconsumption can result in a negative mental health impact. In helping community members prepare, mitigate, respond to, and recover from natural disasters, it is important to acknowledge and discuss the mental health impacts of media overconsumption. Below are media use guidelines to reduce potentially harmful reactions to an event.

1. Be aware of daily media consumption and limit if necessary. This can be tracked through an app and will establish an allotted amount of time to consume media. For example, checking briefly in the morning and evening can keep you up to date while preventing overexposure to distressing imagery.

2. Be aware of your feelings when viewing media coverage about the disaster. If you are feeling anxious or sad, turn it off and do something else.

3. Avoid articles with sensationalist titles or graphic imagery.

4. Disable social media notifications once the disaster is over.

5. Use social media as a positive tool and as a way to "check in" to let friends and family know you are safe.

6. Use media as a means of processing the event and sharing experiences.

7.If you suspect someone may be suffering mental health impacts due to an increase in media consumption, talk with the person, explain the dangerous impacts, and encourage them to follow the guidelines above. Assist them in downloading apps, developing time limits, and avoiding sensationalist stories. 


\section{References}

American Psychiatric Association. (2013). Trauma- and Stressor-Related Disorders. In Diagnostic and Statistical Manual of Mental Disorders ( $5^{\text {th }}$ ed.). Washington, D.C.: American Psychiatric Association.

Evans, J., \& Heiberger, S. (2016). Agricultural Media Coverage of Farm Safety: Review of the Literature. Journal of Agromedicine, 21(1), 91-105. https://doi.org/10.1080/105 9924X.2015.1106376

Hall, B. J., Xiong, Y. X., Yip, P., Lao, C. K., Shi, W., Sou, E., Chang, K., Wang, L., \& Lam, A. (2019). The Association between Disaster Exposure and Media Use on Post-Traumatic Stress Disorder Following Typhoon Hato in Macao, China. European Journal of Psychotraumatology, 10(1), 1558709. https://doi.org/10.1080/20008198.2018.1558709

Irasema, A. A. (2002). Geomorphology, Natural Hazards, Vulnerability and Prevention of Natural Disasters in Developing Countries. Geomorphology, 47(2-4), 107-124. https://doi.org/10.1016/S0169-555X(02)00083-1

Jaeger, P., Shneiderman, B., Fleischmann, K., Preece, J., Qu, Y., \& Wu, P. (2007). Community Response Grids: E-government, Social Networks, and Effective Emergency Management. Telecommunications Policy 31, 592-604. 10.1016/j.telpol.2007.07.008.

Leaning, J., \& Guha-Sapir, D. (2013). Natural Disasters, Armed Conflict, and Public Health. N. Engl. J. Med. 369, 1836-42.

Neria, Y., \& Sullivan, G. M. (2011). Understanding the Mental Health Effects of Indirect Exposure to Mass Trauma through the Media. JAMA, 306(12), 1374-1375. https://doi. org/10.1001/jama.2011.1358

Norris, F. H., Stevens, S. P., Pfefferbaum, B., Wyche, K. F., \& Pfefferbaum, R. L. (2008). Community Resilience as a Metaphor, Theory, Set of Capacities, and Strategy for Disaster Readiness. American Journal of Community Psychology, 41(1-2), 127-150.

Palen, L., \& Vieweg, S. (2008). The Emergence of Online Widescale Interaction in Unexpected Events: Assistance, Alliance \& Retreat. Proceedings of the $11^{\text {th }}$ ACM 2008 Conference on Computer-Supported Cooperative Work, 117-126.
Pfefferbaum, B., Newman, E., Nelson, S. D., Nitiéma, P., Pfefferbaum, R. L., \& Rahman, A. (2014). Disaster Media Coverage and Psychological Outcomes: Descriptive Findings in the Extant Research. Curr. Psychiatry Rep., 16(464). https://doi.org/10.1007/s11920-014-0464-x

Rogers, D. (2013). Secondary Traumatic Stress in the General Public Following Disasters: A Personal Experience. Policy Research Associates. https://www.prainc. com/secondary-traumatic-stress-in-the-general-publicfollowing-disasters-a-personal-experience/

Smith, A. B. (2020). 2010-2019: A Landmark Decade of U.S. Billion-Dollar Weather and Climate Disasters. NOAA's National Centers for Environmental Information (NCEI). https://www.climate.gov/news-features/blogs/ beyond-data/2010-2019-landmark-decade-us-billiondollar-weather-and-climate

Solomon, S. D. (1989). Research Issues in Assessing Disaster's Effects. In R. Gist \& B. Lubin (Eds.), Psychosocial Aspects of Disaster (pp. 308-340). New York: Wiley.

Tandoc, Jr., E. C., \& Takahashi, B. (2017). Log in if you survived: Collective Coping on Social Media in the Aftermath of Typhoon Haiyan in the Philippines. New Media \& Society, 19(11), 1778-1793.

Yeung, N. C. Y., Lau, J. T. F., Yu, N. X., Zhang, J., Xu, Z., Choi, K. C. ... Lui, W. W. S. (2018). Media exposure related to the 2008 Sichuan Earthquake predicted probable PTSD among Chinese adolescents in Kunming, China: A Longitudinal Study. Psychological Trauma: Theory, Research, Practice, and Policy, 10(2), 253-262. 